\title{
Evaluation of Total Fatty Acid Profiles of Two Types of Low-Fat Goat Milk Ice Creams
}

\author{
Christopher E. McGhee, Binod P. Gupta, Young W. Park* \\ Georgia Small Ruminant Research \& Extension Center, Fort Valley State University, Fort Valley, USA \\ Email: "parky@fvsu.edu
}

Received 19 November 2014; revised 26 December 2014; accepted 4 January 2015

Copyright (C) 2015 by authors and Scientific Research Publishing Inc.

This work is licensed under the Creative Commons Attribution International License (CC BY).

http://creativecommons.org/licenses/by/4.0/

(c) (i) Open Access

\section{Abstract}

Effects of frozen-storage on fatty acids profiles and basic nutrient contents of two types of low-fat caprine milk ice creams were investigated during $0,2,4,8$ weeks of storage at $-18^{\circ} \mathrm{C}$. Two types of the experimental low-fat soft-serve goat ice creams were manufactured using whole (full-fat) milk and $2 \%$ fat goat milk with addition of commercial powdered vanilla flavor pre-mix containing $0.25 \%$ fat (Alpha Freeze, D466-A9047, Tampa, FL, USA). Fatty acid concentrations were quantified using a Thermo Electronic gas chromatography (GC)-MS (Model TRACE GC Ultra, Austin, TX, USA) equiped with an automatic sampler (Model AS-3000, Thermo Electronic Co.). The results showed that fat content was the only basic nutrient component exhibited the difference between the two types of ice creams, while no other components have shown differences between the two low-fat ice creams during the storage periods. The level of lauric acid (C12:0) was the highest among all 16 fatty acids, followed by palmitic (C16:0), linoleic (C18:1), and myristic acid (C14:0). The high levels of the medium chain fatty acids (C12:0 and C14:0) might have been derived from the goat milk as well as the palm oil asa part of the ingredients in the commercial ice cream premix. Among long chain fatty acids, palmitic acid (C16:0) was the highest, followed by oleic acid (C18:1) and stearic acid (C18:0). All of the long chain fatty acids contents were significantly higher $(\mathrm{P}<0.05$ or 0.01$)$ in whole milk ice cream than those in 2\% fat ice cream, except for the C22:0 and C24:00 acids. It was concluded that mean levels of the individual fatty acids in the caprine ice creams were significantly influenced by the types of milk fat used in the ice creams, but not by storage periods and storage $\times$ fat type interaction effects.

\section{Keywords}

Goat Milk, Ice Cream, Low-Fat, Fatty Acid Profiles, Storage

\footnotetext{
${ }^{*}$ Corresponding author.
} 


\section{Introduction}

Ice cream is one of the most popular frozen desserts around the world. In the recent report [1], the volume of ice cream market in the US amounted to 1.52 billion gallons (5.75 billion liters). Kilara and Chandan [2] showed that the amount of ice cream market in the US comprised $86.7 \%$ of the total volume of all frozen desserts, and the rest of the market consisted of frozen yogurt, water/fruit ices, and sherbet.

Although ice cream is the most highly demanded dessert food, it typically contains $10 \%-16 \%$ fat, which is detrimental for good health, since dietary fat has been implicated with incidences of atherosclerosis, coronary heart diseases, diabetes, cancer and other diseases [3]-[5]. In recent years, consumption of reduced or low-fat dairy products has been increasingly popular among health-conscientious consumers [6]. To this end, the dairy industry recently has developed a variety of low-fat and fat-free ice cream and other dairy products [7] [8].

The low-fat ice creams, however, have less desirable flavor and textural qualities, compared to the traditional ice creams. Since texture plays an important role in sensory quality and consumer acceptability of ice cream, reduction in milk fat can cause serious textural and flavor defects such as coarseness and iciness, crumbly body, shrinkage and flavor defects in dairy foods including ice cream products [9]-[12]. The ice cream manufacturers have used milk fat replacers in order to produce their products that meet the demands of health-conscious consumers as well as to increase the overall acceptability of low-fat foods [13] [14].

Goat milk ice cream may have certain nutritional advantages over cow milk counterparts due to the differences in nutrient composition between bovine and caprine milk. Caprine milk contains higher short and medium chain fatty acids (MCT) than cow milk, which are beneficial for human nutrition and medicine [15]-[17]. Goat, cow, sheep and human milks contain 2.3, 2.4, 3.8, and $1.8 \mathrm{~g} / 100 \mathrm{~g}$ saturated fatty acids, respectively, suggesting that human milk has lower saturated fat than the 3 major dairy species milks. Human milk also has higher levels of mono- and poly-unsaturated fatty acids (MUFA and PUFA) among the 3 species milks [18]. Interestingly, human milk also has significantly higher content of cholesterol compared to the 3 animal species milks. Goat milk has higher monounsaturated fatty acid than cow milk [18], which was somewhat different from the other report [19]. These compositional differences in fat moieties of milk among species would have certain effects on fatty acid compositions among ice creams made from different species of milk.

Although many studies may have been conducted on fatty acid compositions of various types of cow and other species milk ice creams, very few scientific reports have been available on fatty acid profiles of goat milk ice cream products due probably to exotic and small scale food item as well as the lack of scientific research supports and interests by government, industry and academia. Therefore, the objectives of this study were to: 1) investigate differences in profiles of total fatty acid compositions between two types of low-fat caprine ice creams made of $2 \%$ fat and whole goat milk; and 2) compare the effect of $0,2,4$, and 8 weeks frozen-storage at $-18^{\circ} \mathrm{C}$ on fatty acid compositions between the two types of low-fat goat milk ice creams.

\section{Materials and Methods}

\subsection{Experimental Design}

The study was conducted in a $3 \times 2 \times 4$ factorial experiment. Three different batches of goat milk ice creams were manufactured using two different levels of low-fat as $2 \%$ and whole (3.64\%) goat milk. The 2 levels of low fat goat milk ice creams were manufactured and stored at $-18^{\circ} \mathrm{C}$ for four different storage periods as $0,2,4$ and 8 weeks. The effects of two main factors and their interactions on total fatty acid compositions of the experimental goat milk ice cream were evaluated. All experimental ice cream samples were packaged in $227 \mathrm{~g}(8 \mathrm{oz})$ styrofoam cups, and analyzed for basic nutrient contents and fatty acid profiles of two types of caprine milk ice creams at $0,2,4$, and 8 weeks storage periods.

\subsection{Manufacture of Ice Creams}

Manufacture of Whole Milk and 2\% Fat Milk Ice Creams

1) Whole goat milk ice cream

A $3.76 \mathrm{~L}$ (one gallon) of whole goat milk was pasteurized at $64^{\circ} \mathrm{C}$ for 30 minutes using a Hoegger Table Top pasteurizer (54M-5, Fayetteville, IN, USA). After pasteurization, $1.3 \mathrm{~kg}$ of commercial vanilla mix (Alpha Freeze, D466-A9047, Tampa, USA) powdered ice cream premix was added to the pasteurized whole milk, and mixed thoroughly using a hand mixer. The commercial ice cream premix was composed of sugar, corn syrup 
solids, coconut oil, natural flavor, sodium caseinate (a milk derivative), sodium \& potassium phosphate, guar gum, mono \& diglycerides, xanthan gum, and soy lecithin. The total fat content of the commercial ice cream premix was $0.25 \%$. The mixture of fluid goat milk and powder premix was poured into two separate tanks in the Sani Service cream machine (A5223P, Mooresville, IN, USA), where the mixture was frozen and blended until

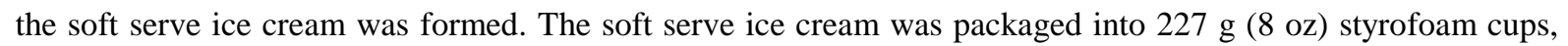
labeled, and stored in a chest freezer (Frigidaire, Model GLFC2528FW, Raleigh, NC, USA) at $-18^{\circ} \mathrm{C}$ for 0, 2, 4, and 8 weeks until chemical and fatty analyses. The ice cream was made at the dairy plant of the Georgia Small Ruminant Research and Extension Center, Fort Valley State University, Fort Valley, GA, USA.

2) Manufacture of $2 \%$ fat goat milk ice cream

The $2 \%$ fat goat milk ice cream was manufactured using the skim goat milk and goat cream produced from the separation of the whole goat milk. The skim milk was produced by separating cream from whole goat milk using an electric cream separator (125 L/h, Clair Co. Model 17,584, Althofen, Austria). Accurate amount of goat milk cream was calculated using the Pearson Square Method. The exactly calculated amounts of cream and skim milk were combined to make the $2 \%$ fat milk. The final fat content of the $2 \%$ fat milk was determined by using a Milk-O-Scan (Model FT2, Hillerod, Denmark). The 2\% milk was pasteurized, and then $2 \%$ fat ice cream was manufactured as the same procedure performed for the whole milk ice cream. The $2 \%$ fat ice cream was assigned to the same experimental treatments as the whole milk ice cream, and performed all the corresponding chemical and fatty acids analyses.

\subsection{Basic Nutrient Analysis}

\subsubsection{Fat Content}

The percent fat of all experimental ice cream samples was determined using the Babcock procedure [20] [21]. The ice cream was melted at room temperature and then 9 grams of the ice cream was weighed and transferred into the Babcock bottle for the analysis. Fat and other basic nutrients for original milk samples were tested by the Milk-O-Scan machine (Model FT2, Hillerod, Denmark).

\subsubsection{Protein Content}

Protein content was determined using a carbon/nitrogen analyzer (Vario MAX CN Elementar Americas, Inc. Mt. Laurel, NJ, USA). Nitrogen contents of the ice cream samples were first determined by the Vario MAX CN analyzer, and then the \% $\mathrm{N}$ was multiplied by 6.38 to calculate protein contents of the ice creams.

\subsubsection{Dry Matter and Ash Content}

Dry matter was determined by oven drying at $105^{\circ} \mathrm{C}$ method overnight [22]. Amounts of ash of ice cream samples were analyzed by dry ashing method [22]. A 2 grams sample was placed in a muffle furnace at $600^{\circ} \mathrm{C}$ for overnight, and cooled to room temperature in a desiccator before determining the ash contents.

\subsection{Fatty Acid Analysis}

\subsubsection{Lipid Extraction}

Two grams of ice cream sample were measured into a $100 \mathrm{~mL}$ beaker, and then $8 \mathrm{~mL}$ of methanol and $18 \mathrm{~mL}$ of chloroform was added and homogenized for 30 seconds using a homogenizer. Once homogenization was complete, $9 \mathrm{~mL}$ of additional chloroform was added to the beaker and homogenized for another 30 seconds. Next, 9 $\mathrm{mL}$ of zinc acetate $(0.115 \mathrm{~g}$ zinc acetate $/ 5 \mathrm{~mL}$ of deionized water) was added and once again homogenized for 30 seconds. The contents were then poured into a $125 \mathrm{~mL}$ separatory funnel and placed in refrigeration until two layers were separated, which normally takes 2 hours. Once the two layers were visibly present, the bottom fat layer was drained off into a glass tube with appropriate cap and stored in a freezer $\left(-18^{\circ} \mathrm{C}\right)$ until fatty acid analysis by gas chromatography.

\subsubsection{Preparation of FAME (Fatty Acid Methyl Esters)}

Four milliliters of $0.5 \mathrm{~N}$ methanolic sodium hydroxide and boiling beads were added to the 0.1 grams of extracted fat in the $125 \mathrm{~mL}$ reaction flask. The flask was then attached to a water-cooled condenser, and its contents refluxed for 10 minutes. After refluxing, $5 \mathrm{~mL}$ of $\mathrm{BF}_{3}$-methanol reagent (Supleco Inc., Bellafonate, PA, USA) were added to the reaction flask through the condenser, and the contents of the flask refluxed for an addi- 
tional minute. Once the flasks were removed and cooled, enough saturated $\mathrm{NaCl}$ solution was added to the flask to float the pentane solution containing the methyl esters in the neck of the flask. Lastly, five to seven milliliters of the pentane solution containing the methyl esters were transferred into a test tube, and a small amount of anhydrous sodium sulfate was added to dry the pentane solution.

\subsubsection{Gas Chromatographic (GC) Analysis of FAMEs}

The prepared fatty acid methyl esters (FAME) were analyzed using a Thermo Electronic (Austin, TX, USA) gas chromatography-MS (Model TRACE GC Ultra) equipped with an automatic sampler (Model AS-3000, Thermo Electronic Co.). A fused silica capillary column $(0.25$-mm i.d. $\times 0.25 \mu \mathrm{m}$ film thickness, $\times 60-\mathrm{m}$; SP-2380 Supelco, Inc., Bellefonte, PA, USA) was used to separate the methyl esters, which were detected with a flame ionization detector (FID). The injection temperature was programmed with a range from $10^{\circ} \mathrm{C}$ to $220^{\circ} \mathrm{C}$ at $2{ }^{\circ} \mathrm{C} / \mathrm{min}$. Helium was used as a carrier gas, with a flow rate of $1.6 \mathrm{~mL} / \mathrm{min}$ and a split ratio of 30:1. The identification of individual FAME from the sample was done by matching the retention time of the unknown FAME with that of known FAME standard mixtures (Alltech Associates, Inc., Deerfield, IL, USA; Sigma-Aldrich Corp., Bellefonte, PA, USA).

\subsection{Statistical Analysis}

All experimental data of three different batches of goat milk ice creams made with 2 levels of milk fat (whole milk and $2 \%$ fat milk) were analyzed for the effect of main factors and their interactions on nutritional, lipolytic, textural, and sensory characteristics by the method of Steel and Torrie [23]. All data were also analyzed by analysis of variance, Duncan's multiple mean comparisons between main factors using general linear model of SAS program [24].

\section{Results and Discussion}

The basic nutrient contents (\%) of $2 \%$ fat and whole milk goat ice creams have shown in Table 1 . It was apparent that the whole milk goat ice cream contained significantly higher $(\mathrm{P}<0.05)$ fat content than $2 \%$ fat goat ice cream. Dry matter and carbohydrate contents of $2 \%$ fat ice cream were slightly higher than those of whole goat milk ice cream counterpart, which may be due to the replacement of fat by slightly higher sugar content of the ice cream premix in the $2 \%$ fat ice cream. However, protein and ash contents were virtually similar between the two products.

The profiles of fatty acid compositions (mean and standard deviation) of the whole (full-fat) goat milk ice cream and 2\% fat goat ice cream are listed in Table 2. It was shown that the goat milk ice creams contained 16 different fatty acids from butyric acid (C4:0) to lignoceric acid (C24:0), which would be derived from the original goat milk and in addition to the ingredients of the premix such as palm oil.

The highest concentration (mole\%) of fatty acid was lauric acid (C12:0), followed by palmitic (C16:0), linoleic (C18:1), and myristic acid (C14:0). The high levels of the medium chain fatty acids (C12:0 and C14:0) might have been derived from the palm oil in the ice cream premix. The profiles of short chain and medium chain fatty acids in both types of the ice creams are shown in Figure 1 and Table 2. Although goat milk has been known to contain high amounts of short and medium chain fatty acids [15]-[17] [25] [26], the greatest level of lauric acid among the short chain and medium chain fatty acids as well as among all fatty acids of the ice creams detected in this study was a unique and unusual phenomenon. It appeared that the palm oil in the premix contributed to the elevated myristic acid in both of the experimental low-fat goat ice cream products. Furthermore, $2 \%$ fat ice cream contained significantly $(\mathrm{P}<0.001)$ greater $\mathrm{C} 12: 0$ acid than that of whole milk (full fat)

Table 1. Basic nutrient compositions (\%) of $2 \%$ and whole milk goat ice creams.

\begin{tabular}{cccccccccccc}
\hline & \multicolumn{2}{c}{ Dry matter } & \multicolumn{2}{c}{ Fat } & \multicolumn{2}{c}{ Protein } & \multicolumn{2}{c}{ Ash } & \multicolumn{2}{c}{ Carbohydrate } \\
\cline { 2 - 13 }$y$ & Mean & SD & Mean & SD & Mean & SD & Mean & SD & Mean & SD \\
\hline $2 \%$ milk & 34.15 & 1.70 & $3.84^{\mathrm{b}}$ & 0.13 & 2.80 & 0.16 & 1.58 & & 25.94 & 0.06 \\
Whole milk & 33.28 & 1.70 & $5.31^{\mathrm{a}}$ & 0.57 & 2.90 & 0.24 & 1.58 & 0.08 & 23.47 & 0.12 \\
\hline
\end{tabular}

SD: Standard deviation. ${ }^{\mathrm{a}, \mathrm{b}}$ Means with different superscripts within a same column are different $(\mathrm{P}<0.05)$. 
Table 2. Comparison of mean concentrations (\% mole) across storage periods of 16 different fatty acids between whole milk and $2 \%$ milk goat ice creams.

\begin{tabular}{|c|c|c|c|c|}
\hline \multirow{2}{*}{ Fatty acid } & \multicolumn{2}{|c|}{ Whole milk ice cream } & \multicolumn{2}{|c|}{$2 \%$ fat ice cream } \\
\hline & mean & SD & mean & SD \\
\hline $\mathrm{C} 4: 0$ & $2.58^{\mathrm{b}}$ & 0.71 & $3.35^{\mathrm{a}}$ & 1.35 \\
\hline C6:0 & $0.99^{\mathrm{a}}$ & 0.06 & $0.89^{\mathrm{b}}$ & 0.06 \\
\hline C8:0 & $4.17^{\mathrm{b}}$ & 0.22 & $4.91^{\mathrm{a}}$ & 0.34 \\
\hline C10:0 & 6.78 & 0.33 & 6.77 & 0.47 \\
\hline $\mathrm{C} 12: 0$ & $25.21^{\mathrm{b}}$ & 1.22 & $31.94^{\mathrm{a}}$ & 1.89 \\
\hline C14:0 & $14.43^{\mathrm{b}}$ & 0.53 & $16.21^{\mathrm{a}}$ & 0.75 \\
\hline C14:1 & 0.14 & 0.06 & 0.11 & 0.05 \\
\hline C16:0 & $19.26^{\mathrm{a}}$ & 0.59 & $17.33^{\mathrm{b}}$ & 0.78 \\
\hline C16:1 & $0.41^{\mathrm{a}}$ & 0.02 & $0.33^{\mathrm{b}}$ & 0.03 \\
\hline C18:0 & $7.17^{\mathrm{a}}$ & 0.29 & $6.85^{\mathrm{b}}$ & 0.32 \\
\hline C18:1 & $15.94^{\mathrm{a}}$ & 2.18 & $8.50^{\mathrm{b}}$ & 3.96 \\
\hline C18:2 & 2.06 & 0.06 & 2.06 & 0.10 \\
\hline C18:3 & $0.63^{\mathrm{a}}$ & 0.03 & $0.48^{\mathrm{b}}$ & 0.03 \\
\hline C20:0 & 0.06 & 0.01 & 0.06 & 0.01 \\
\hline C22:0 & 0.12 & 0.03 & 0.13 & 0.02 \\
\hline $\mathrm{C} 24: 0$ & $0.04^{\mathrm{b}}$ & 0.01 & $0.07^{\mathrm{a}}$ & 0.03 \\
\hline
\end{tabular}

\footnotetext{
${ }^{\mathrm{a}, \mathrm{b}}$ Means with different superscripts within the same rows are different $(\mathrm{P}<0.05$ or 0.01$)$. SD: Standard deviation.
}

whole mean $\quad 2 \%$ mean

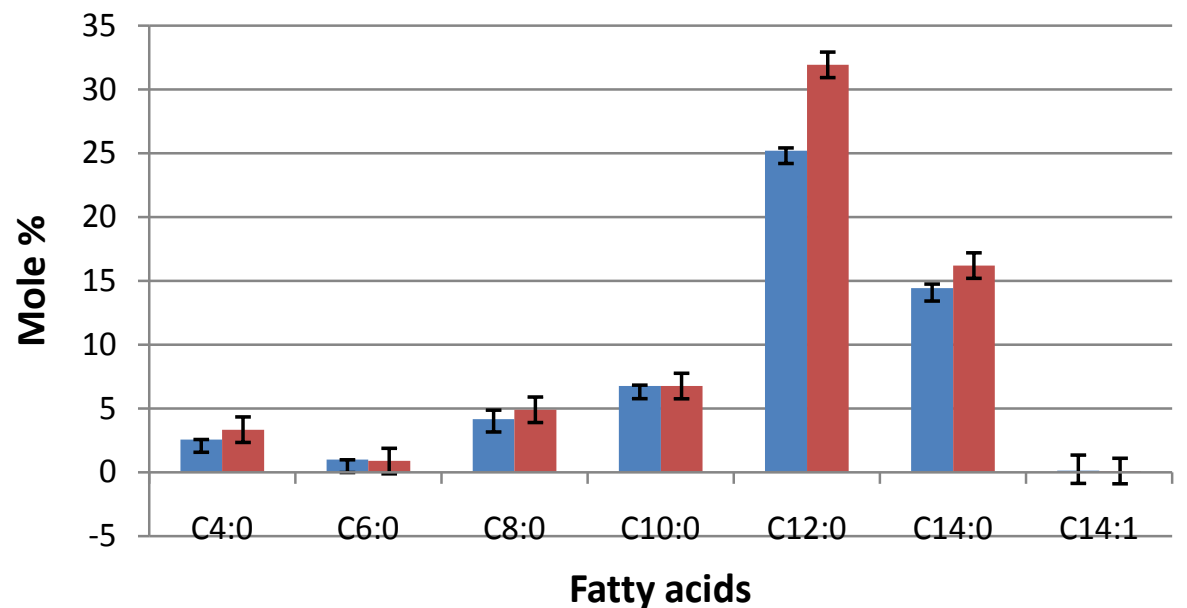

Figure 1. Profiles of overall mean contents (mole \%) of short and medium chain fatty acids of whole goat milk ice cream and $2 \%$ fat goat milk ice cream. 


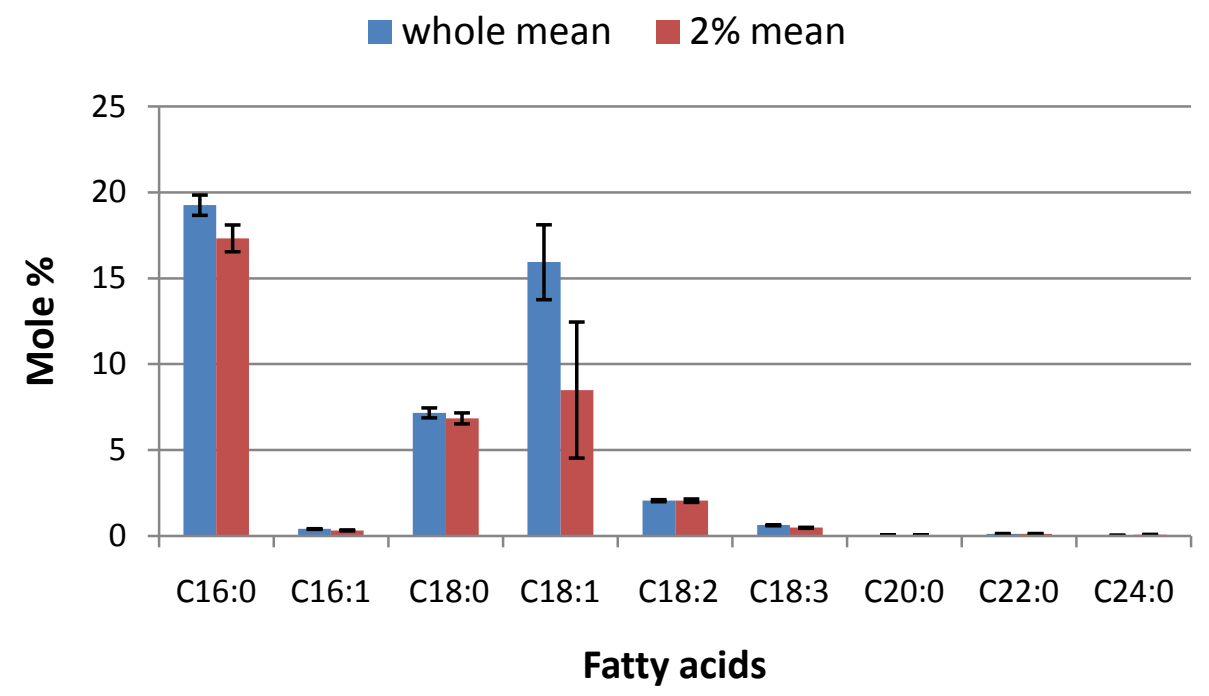

Figure 2. Profiles of overall mean contents (mole \%) of long chain fatty acids of whole goat milk ice cream and $2 \%$ fat goat milk ice cream.

ice cream, implying that the replaced fat by the powdered ice cream premix in the $2 \%$ fat ice cream might have accounted for the increased C12:0 acid compared to the level of C12:0 in the whole milk ice cream which has not been likely to be changed from the original fat composition of the goat milk. This fact has been proven and also has been confirmed by the earlier reports on goat milk composition profiles by Gonc et al. [27] and Jenness [16], where they reported that the levels of C10:0 and C14:0 acid levels in goat milk are much higher than that of the C12:0 acid.

In light of long chain fatty acids concentrations, palmitic acid (C16:0) was the highest, followed by oleic acid (C18:1) and stearic acid (C18:0) (Figure 2 and Table 2). All of the long chain fatty acids were significantly higher in whole milk ice cream than those in 2\% fat ice cream, except the C22:0 and C24:00 acids (Table 2). Among the unsaturated fatty acids, the level of oleic acid was greatest, and whole milk ice cream contained substantially higher $(\mathrm{P}<0.001)$ and approximately double amount of $\mathrm{C} 18: 1$ acid compared to that of $2 \%$ fat ice cream (Figure 2 and Table 2). On the other hand, the variation of the levels of C18:1 acid were much greater than the other long chain fatty acids in both types of ice creams. This may indicates that the partial removal of the cream in $2 \%$ fat goat milk might have removed proportionally more C18:1 acid than the other fatty acids. It means that the processes of removal of some fat and standardization of $2 \%$ fat milk may have caused alteration of fatty acid composition of $2 \%$ fat ice cream compared to that of the whole milk fat ice cream. Smet et al. [28] studying the influence of altering milk fatty acid composition and process parameters on the quality of bovine milk ice cream ( $8 \%$ fat), found that high-quality ice cream can be produced with an altered fatty acid composition without any alteration in the conventional production processes such as heat treatment, fat droplet size and homogenization pressure, etc.

The analysis of variance for the effects of the main factors and interactions on fatty acid compositions of the two experimental low-fat goat ice creams revealed that there were significant differences between two fat levels (2\% fat and whole goat milk) ice cream in the levels of C4:0 (P < 0.05), C6:0 (P < 0.01), C8:0 (P < 0.001), C12:0 (P < 0.001), C14:0 (P < 0.001), C16:0 ( $\mathrm{P}<0.001)$, C16:1 $(\mathrm{P}<0.001), \mathrm{C} 18: 0(\mathrm{P}<0.05), \mathrm{C} 18: 1(\mathrm{P}<$ 0.001), C18:3 ( $\mathrm{P}<0.001)$, and C24:0 ( $<0.05)$, respectively, while no differences were found in C10:0, C14:1, C18:2, C20:0, and C22:0 between the two low-fat levels of the goat milk ice creams (Table 3). The most substantial difference in the level of the fatty acids was lauric acid (C12:0) between the two types of the low-fat ice creams. However, the 5 different periods of storage time did not make any difference in all of the fatty acids. Likewise, none of the milk type $\times$ storage time interactions has affected the levels of all fatty acids (Table 3 ).

As far as the effect of storage periods goes, none of the $\mathrm{F}$ values for the differences in fatty acid compositions between storage periods were significant (Table 3). However, if the pooled means of fatty acid contents of the two types of ice creams were compared among storage periods by Duncan's multiple mean comparison, very small differences between storage periods were appeared $(\mathrm{P}<0.05)$ for a few cases such as C14:0, C16:0, C18:3 
Table 3. Summary of Analysis of Variance (F-Values) for effects of main factors and their interactions on individual fatty acid content (mole \%) of 2 types of goat ice creams.

\begin{tabular}{|c|c|c|c|}
\hline Fatty Acid & Milk Type & Storage Time & Milk Type $\times$ Storage Time \\
\hline $\mathrm{C} 4: 0$ & $5.64^{*}$ & 0.34 & 0.35 \\
\hline C6:0 & $14.80^{* *}$ & 0.16 & 0.38 \\
\hline C8:0 & $50.95^{* * *}$ & 0.58 & 0.77 \\
\hline $\mathrm{C} 10: 0$ & 0.03 & 0.30 & 0.29 \\
\hline C12:0 & $117.72^{* * *}$ & 0.80 & 0.96 \\
\hline C14:0 & $48.75^{* *}$ & 1.02 & 0.88 \\
\hline C14:1 & 1.25 & 0.17 & 0.52 \\
\hline C16:0 & $42.30^{* * *}$ & 0.69 & 0.05 \\
\hline C16:1 & $48.45^{* * *}$ & 0.44 & 0.37 \\
\hline C18:0 & $6.18^{*}$ & 0.76 & 0.14 \\
\hline C18:1 & $40.13^{* * * *}$ & 0.91 & 0.73 \\
\hline C18:2 & 0.01 & 0.68 & 0.19 \\
\hline C18:3 & $187.3^{* * *}$ & 0.68 & 0.16 \\
\hline C20:0 & 1.24 & 0.72 & 0.45 \\
\hline $\mathrm{C} 22: 0$ & 0.36 & 2.18 & 1.29 \\
\hline C24:0 & $4.58^{*}$ & 0.74 & 0.12 \\
\hline
\end{tabular}

${ }^{*} \mathrm{P}<0.05 ;{ }^{* * *} \mathrm{P}<0.01 ;{ }^{* * *} \mathrm{P}<0.001$

and C22:0. This indicates that in certain cases, pooled mean differences in fatty acid contents between storage periods can be significant by separation of Duncan's multiple mean comparison procedure, even if the F values were low and insignificant.

\section{Conclusions}

The effects of the 2 main factors and interactions on fatty acid compositions of the two experimental low-fat goat milk ice creams revealed that the milk fat type showed highly significant difference in most of the individual fatty acids, whereas storage time did not have any influence on the levels of all 16 fatty acids. In addition, none of storage periods as well as milk fat type $\times$ storage time interactions showed any significant effects on the levels of all fatty acids tested. The most substantial difference was found in the level of lauric acid (C12:0) between the two types of ice creams.

In regard to long chain fatty acids, the level of oleic acid (C18:1) was much greater than those of other long chain fatty acids in both types of goat ice creams with higher variations. Further studies are necessary to quantify what fatty acids and how much amounts are transferred/removed as well as what type of biochemical mechanism was involved in the changes in individual fatty acid contents during standardization procedures of the $2 \%$ fat milk, which may influence on the storage stability and consumer acceptability of the goat milk ice cream products.

\section{Acknowledgements}

This research was supported by the Strengthening the Minority Serving Institutions Project (FVSU Project \# 331079) entitled "Advancing Graduate Education in the STEM Disciplines for the Underserved African American and Low Income American Population" funded by the United States Department of Education. Authors appreciate Jolethia Jones for assisting manufacture of goat milk ice creams, and Carlton Green and Schauston 
Miller for preparation of goat milk and its pasteurization, and procurement of the commercial powdered ice cream premix and other supplies for the ice cream manufacture.

\section{References}

[1] USDA (2012) National Agriculture Statistics Service. http://www.idfa.org/news--views/media-kits/ice-cream/ice-cream-sales-and-trends/

[2] Kilara, A. and Chandan, R.C. (2013) Frozen Dairy Products. In: Park, Y.W. and Haenlein, G.F.W., Eds., Milk and Dairy Products in Human Nutrition, Wiley-Blackwell Publishers, 435-457. http://dx.doi.org/10.1002/9781118534168.ch20

[3] Tunick, M.H. (2000) Rheology of Dairy Foods That Gel, Stretch, and Fracture. The Journal of Dairy Science, 83, 18921898. http://dx.doi.org/10.3168/jds.S0022-0302(00)75062-4

[4] Tunick, M.H., Mackey, K.L., Shief, J.J., Smith, P.W., Cooke, P. and Malin, E.L. (1993) Rheololgy and Microstructure of Low-Fat Mozzarella Cheese. International Dairy Journal, 3, 649-662. http://dx.doi.org/10.1016/0958-6946(93)90106-A

[5] Nouira, W., Park, Y.W., Guler, Z. and Terrill, T.H. (2011) Comparison of Free Fatty Acid Composition between LowFat and Full-Fat Goat Milk Cheeses Stored for 3 Months under Refrigeration. Open Journal of Animal Sciences, 2, $17-23$.

[6] Thayer, A.M. (1992) Food Additives. Chemical Engineering News, 70, 26-44. http://dx.doi.org/10.1021/cen-v070n024.p026

[7] Giese, J. (1996) Fats, Oils, and Fat Replacers. Food Technology, 50, 48-83.

[8] Marshall, R.T., Goff, H.D. and Hartel, R.W. (2003) Ice Cream. 6th Edition, Kluwer/Plenum Publishing, New York, 18, 23, 34, 93, 203.

[9] Berger, K.G. (1990) Ice Cream in Food Emulsions. In: Larsson, K. and Friberg, S.E., Eds., 2nd Edition Marcel Dekker, New York, 367.

[10] Drake, M.A. and Swanson, B.G. (1995) Reduced- and Low-Fat Cheese Technology: A Review. Trends in Food Science and Technology, 6, 366-369. http://dx.doi.org/10.1016/S0924-2244(00)89192-X

[11] Marshall, R.T. and Arbuckle, W.S. (1996) Ice Cream. 5th Edition, Chapman \& Hill, New York.

[12] Johnson, M.E., Kapoor, R., McMahon, D.J., McCoy, D.R. and Narasimmon, R.G. (2009) Reduction of Sodium and Fat Levels in Natural and Processed Cheeses: Scientific and Technological Aspects. General \& Introductory Food Science \& Technology, 8, 252-268. http://dx.doi.org/10.1111/j.1541-4337.2009.00080.x

[13] Devereux, H.M., Jones, G.P., McCormack, L. and Hunter, W.C. (2003) Consumer Acceptability of Low Fat Foods Containing Inulin and Oligofructose. General \& Introductory Food Science \& Technology, 68, 1850-1854. http://dx.doi.org/10.1111/j.1365-2621.2003.tb12341.x

[14] Akahn, A.S., Karagozlu, C. and Unal, G. (2008) Rheological Properties of Reduced-Fat and Low-Fat Ice Cream Containing Whey Protein Isolate and Inulin. European Food Research and Technology, 227, 889-895. http://dx.doi.org/10.1007/s00217-007-0800-z

[15] Park, Y.W. (1994) Hypo-Allergenic and Therapeutic Significance of Goat Milk. Small Ruminant Research, 14, 151-159. http://dx.doi.org/10.1016/0921-4488(94)90105-8

[16] Jenness, R. (1980) Composition and Characteristics of Goat Milk: Review 1968-1979. Journal of Dairy Science, 63, 1605-1630. http://dx.doi.org/10.3168/jds.S0022-0302(80)83125-0

[17] Park, Y.W. and Haenlein, G.F.W. (2006) Therapeutic and Hypo-Allergenic Values of Goat Milk and Implication of Food Allergy. In: Park, Y.W. and Haenlein, G.F.W., Eds., Handbook of Milk of Non-Bovine Mammals, Blackwell Publishers, Oxford, 121-136. http://dx.doi.org/10.1002/9780470999738.ch6

[18] Posati, L.P. and Orr, M.L. (1976) Composition of Foods. Dairy and Egg Products, Raw-Processed-Prepared. Agricultural Handbook No. 8-1, ARS, USDA, Washington DC.

[19] Holland, B., Unwin, I.D. and Bus, D.H., Eds. (1989) Milk Products and Eggs. In: The Composition of Foods, Royal Society of Chemistry, Ministry of Agriculture, Fisheries and Food, Cambridge.

[20] Richardson, G.H. (1985) Standard Methods for the Examination of Dairy Products. 15th Edition, American Public Health Association, Washington DC, p. 327.

[21] AOAC (1996) Official Methods of Analysis. 16th Edition, Association of Official Analytical Chemists, Washington DC.

[22] AOAC (1985) Official Methods of Analysis. 14th Edition, Association of Official Analytical Chemists, Washington DC, No. 43.292. 7.001, 7.009, 7.006.

[23] Steel, R.G.D. and Torrie, J.H. (1960) Principles and Procedures of Statistics. McGraw-Hill, New York, p. 190. 
[24] SAS (2004) SAS Institute Version 9.0. SAS Institute, Inc., Cary, NC, USA.

[25] Jensen, R.G., Ferris, A.N., Lammi-Keefe, C.J. and Henderson, R.A. (1990) Lipids of Bovine and Human Milks: A Comparison. Journal of Dairy Science, 73, 223-240. http://dx.doi.org/10.3168/jds.S0022-0302(90)78666-3

[26] Park, Y.W. (2006) Goat Milk-Chemistry and Nutrition. In: Park, Y.W. and Haenlein, G.F.W., Eds., Handbook of Milk of Non-Bovine Mammals, Blackwell Publishers, Oxford, 34-58. http://dx.doi.org/10.1002/9780470999738.ch3

[27] Gonc, S., Schmid, R. and Renner, E. (1979) Study on the Fatty Acid Pattern of Buffalo and Goat Milk. Milchwiss, 34, 684-686.

[28] Smet, K., De Block, J., Van Der Meeren, P., Raes, K., Dewettinck, K. and Couduzer, K. (2010) Influence of Milk Fatty Acid Composition and Process Parameters on the Quality of Ice Cream. Dairy Science \& Technology, 90, 431-447. http://dx.doi.org/10.1051/dst/2010006 
Scientific Research Publishing (SCIRP) is one of the largest Open Access journal publishers. It is currently publishing more than 200 open access, online, peer-reviewed journals covering a wide range of academic disciplines. SCIRP serves the worldwide academic communities and contributes to the progress and application of science with its publication.

Other selected journals from SCIRP are listed as below. Submit your manuscript to us via either submit@scirp.org or Online Submission Portal.
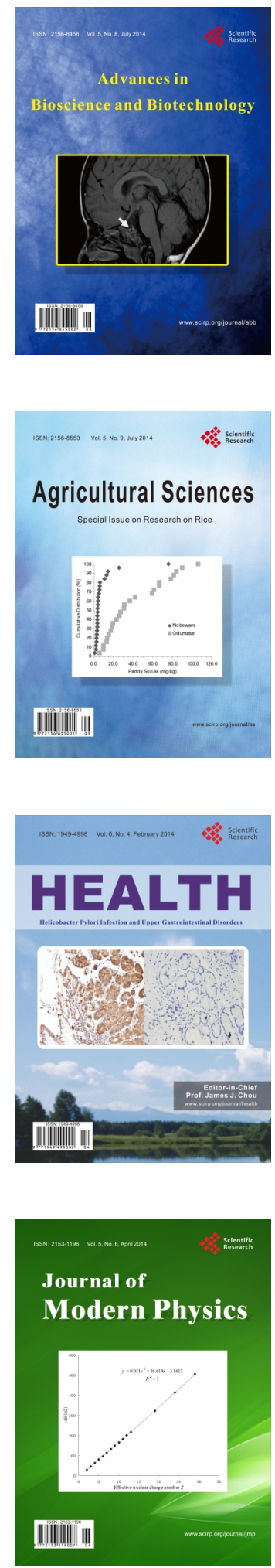
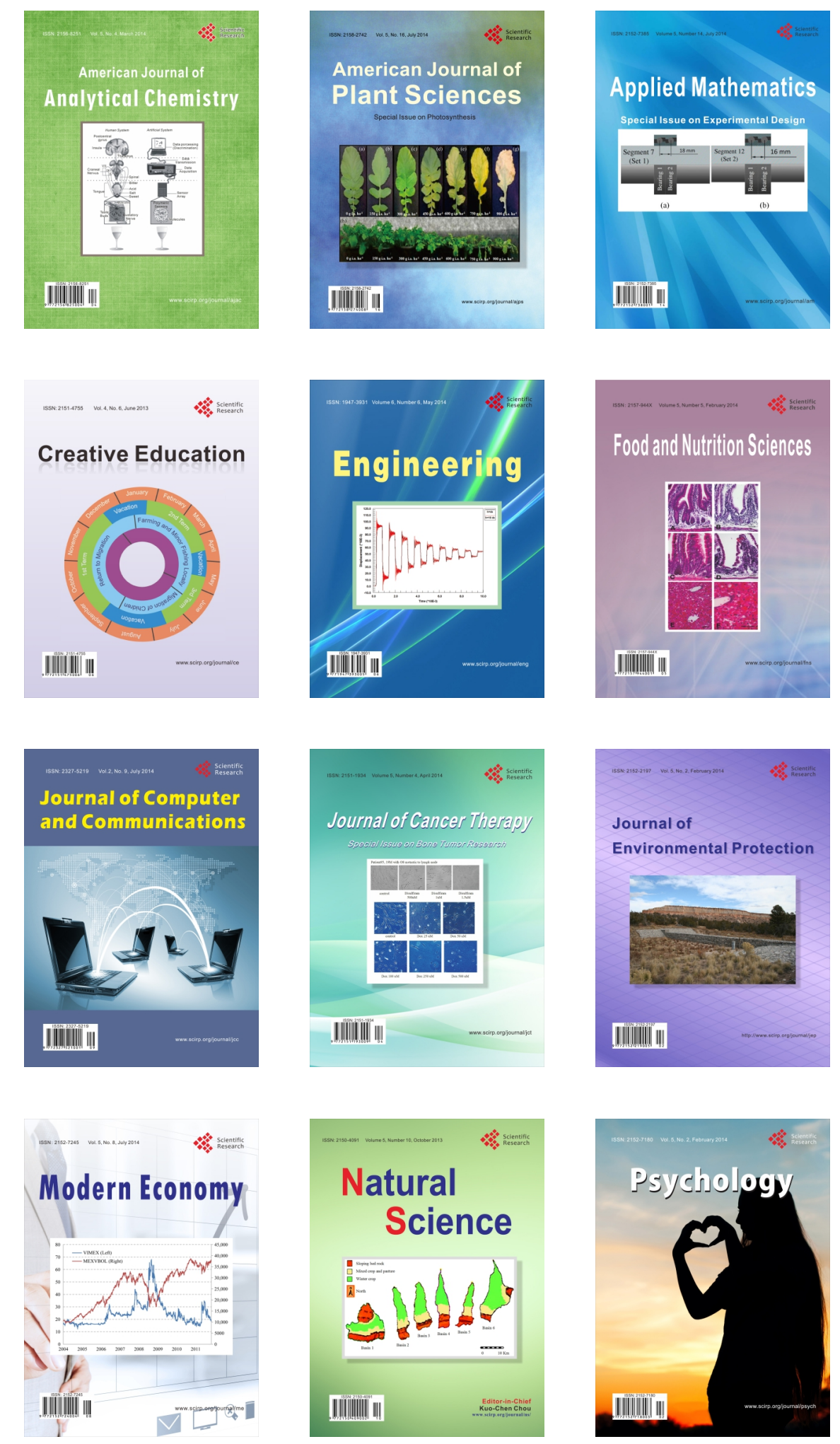